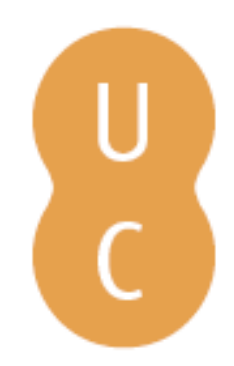

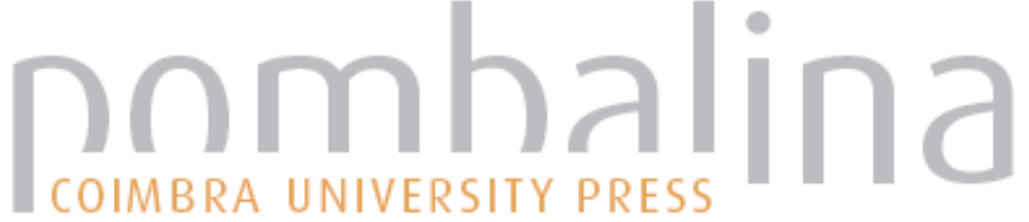

\section{A propaganda do Nacionalsocialismo nos impressos da editora Deutscher Morgen em São Paulo}

\author{
Autor(es): $\quad$ Perazzo, Priscila F.; Prado, Marina Lins \\ Publicado por: Imprensa da Universidade de Coimbra \\ URL \\ persistente: URI:http://hdl.handle.net/10316.2/38999 \\ DOI: \\ DOI:978-989-26-1064-1 (PDF); DOI:http://dx.doi.org/10.14195/978-989- \\ 26-1064-1_5
}

Accessed : $\quad$ 26-Apr-2023 04:00:08

A navegação consulta e descarregamento dos títulos inseridos nas Bibliotecas Digitais UC Digitalis, UC Pombalina e UC Impactum, pressupõem a aceitação plena e sem reservas dos Termos e Condições de Uso destas Bibliotecas Digitais, disponíveis em https://digitalis.uc.pt/pt-pt/termos.

Conforme exposto nos referidos Termos e Condições de Uso, o descarregamento de títulos de acesso restrito requer uma licença válida de autorização devendo o utilizador aceder ao(s) documento(s) a partir de um endereço de IP da instituição detentora da supramencionada licença.

Ao utilizador é apenas permitido o descarregamento para uso pessoal, pelo que o emprego do(s) título(s) descarregado(s) para outro fim, designadamente comercial, carece de autorização do respetivo autor ou editor da obra.

Na medida em que todas as obras da UC Digitalis se encontram protegidas pelo Código do Direito de Autor e Direitos Conexos e demais legislação aplicável, toda a cópia, parcial ou total, deste documento, nos casos em que é legalmente admitida, deverá conter ou fazer-se acompanhar por este aviso.

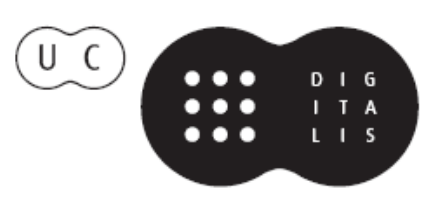


A L B ERTO PENA-RODR ÍGUEZ HELOISA PAULO

COOR D.

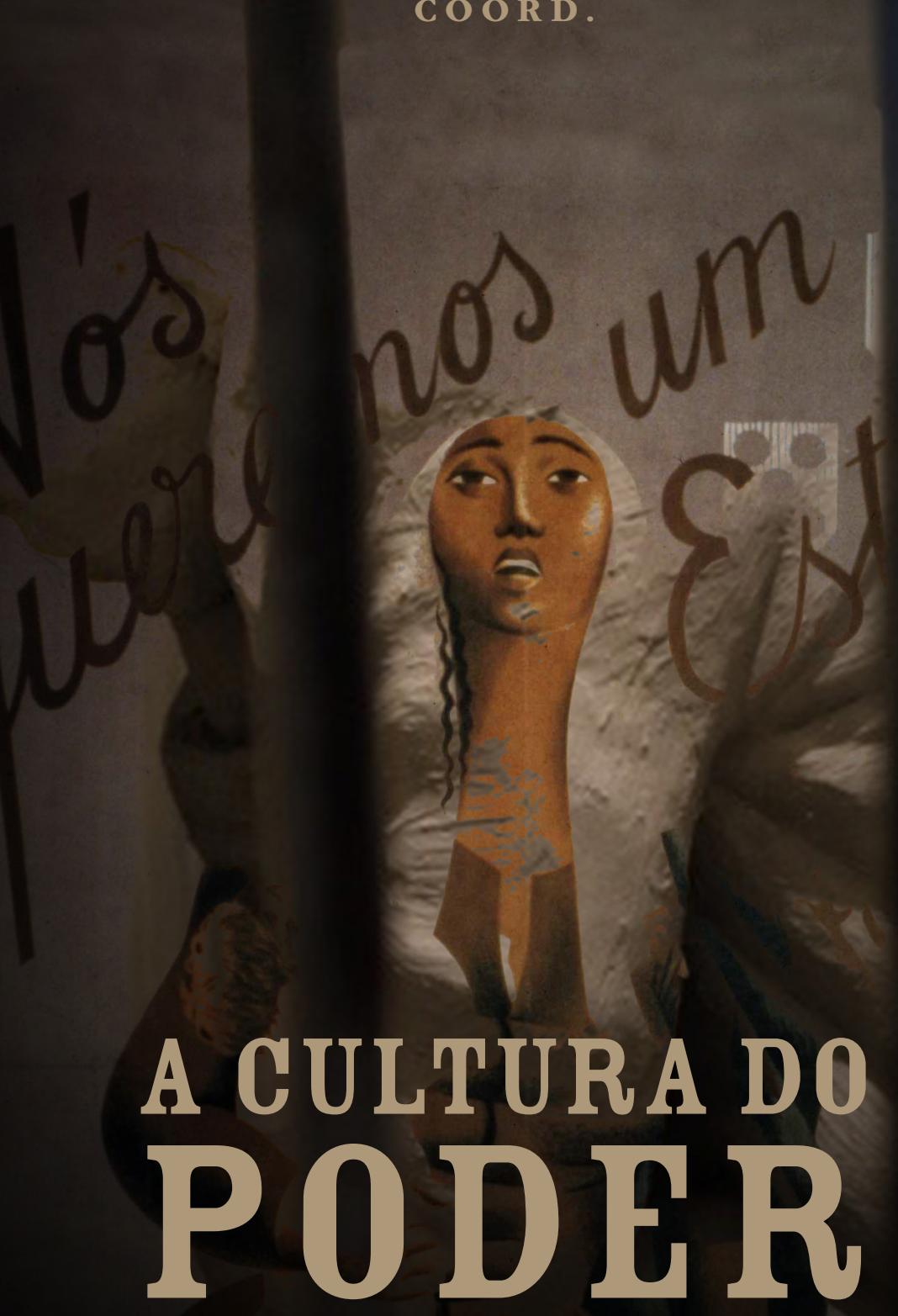

A PROPAGANDA INOS ESTADOS AUTORITÁRIOS 


\section{A PROPAGANDA DO NACIONAL-SOCIALISMO NOS IMPRESSOS DA EDITORA DEUTSCHER MORGEN EM SÃO PAULO}

Priscila F. Perazzo Marina Lins Prado

Esse texto discute as formas de propaganda que possibilitaram a disseminação do nazismo junto à comunidade de origem cultural germânica na primeira metade do século XX, em São Paulo, nas décadas de 1930 e 1940. As ideias do nacional-socialismo de Hitler foram difundidas na comunidade alemã paulista a partir dos impressos que circularam no interior dessa comunidade, no cotidiano das famílias, nas páginas dos jornais.

No interior de uma comunidade cultural - cuja língua alemã representou o vetor de aproximação, identidade e pertencimento - ocorreu uma intensa propaganda política e cultural do nazismo de Hitler, e o alvo foram os alemães radicados no exterior, ou seja, para além da Alemanha. A comunidade de cultura germânica conviveu com a propaganda impressa no seu cotidiano. A circulação de jornais, a publicação de almanaques, os convites para festas e panfletos impressos circulavam no seio da comunidade alemã da capital. E tinham como meio dessa comunicação os próprios jornais alemães, distribuídos no Brasil. Segundo Maria Helena 
Capelato ${ }^{1}$, os meios de comunicação são um dos responsáveis por intensificar as emoções e aquecer as sensibilidades de uma população.

É consenso entre os historiadores que os anos 1930 representaram a consolidação da imprensa burguesa no Brasil - reflexo de um movimento iniciado na Primeira Guerra Mundial. À época, os jornais ofereciam à população uma maneira de compreender melhor o que acontecia no mundo conturbado pela guerra. Já a imprensa, por sua vez, "se via desafiada a consolidar um público fixo e de fazê-los comprar e ler mais"2. Pensando assim, que os representantes da ideologia nazista no Brasil viram na imprensa jornalística uma importante via difusora dos discursos do Partido, para inflamar corações e mentes para essa ideologia política.

Com as inovações tecnológicas no século $\mathrm{XX}$, os meios de comunicação ganharam cada vez mais expressão e inserção nas sociedades urbanas, tornando-se veículos de massa, ou seja, estavam acessíveis, cada vez mais, a um grande número de pessoas. Passou-se a associar a palavra com a imagem, que fora "muito utilizada como peça de propaganda para as massas [...] com novos processos de reprodução de gravuras, juntamente com a imprensa."3. Os jornais se popularizaram e se tornaram veículos formadores de opinião, além de veículos de informação e de propaganda política e ideológica, sobretudo em regimes como o nazista na Alemanha.

${ }^{1}$ CAPELATO, Maria Helena. Propaganda política e controle dos meios de comunicação. In: PANDOLFI, Dulce (org). Repensando o Estado Novo. Rio de Janeiro: Ed. FGV, 1999. Ver também CARNEIRO, Maria Luiza Tucci. Livros proibidos, ideias malditas. 2. Ed. São Paulo: Ateliê Editorial, 2002.

2 ARAÚJO, Nelton S. "Imprensa e Poder nos anos 1930: uma análise historiográfica". In: Anais do VI Congresso Nacional de História da Mídia. Niterói: 2008.

3 QUEIROZ, Adolpho; CARRILHO, Kleber. "Propaganda política e totalitarismo". Revista Comunicação \& Informação, v. 15, n. 2, p. 97-115 , jul./dez. 2012, pp. 106$-107$ 
Dessa forma, o que se viu foi a difusão de um conjunto de discursos e imagens que representavam o pensamento nazifascita em páginas de jornais, como o Deutscher Morgen, publicado na capital, mas ao alcance das comunidades da região metropolitana paulista, disponível ao público às quartas-feiras. Apresentava-se como porta-voz das ideias nacional-socialistas por meio da redação de Hans Henning von Cossel, chefe nacional do Partido Nazista no Brasil. Notícia e publicidade pareciam se fundir. O que fosse notícia deveria ser veiculado como publicidade. As determinações vinham do Ministério da Propaganda da Alemanha e de seu chefe Goebbels. Este propunha que a propaganda fosse simples e orquestrada, adaptada aos diversos públicos e visar um objeto de cada vez, e, sobretudo, "assumir as mais variadas formas possíveis"

O jornal Deutscher Morgen imprimia em suas páginas os dois tipos de propaganda: persuasiva, aquela que se utiliza do próprio meio de comunicação como jornal e rádio, em que o político procura persuadir o outro a se inscrever no partido ou votar em determinada legenda; e a propaganda política sugestiva, que aciona os sentidos e as emoções por meio de signos e símbolos5.

Tomando por base as reflexões de Domenach ${ }^{6} \mathrm{o}$ jornal impresso é apontado como um dos principais instrumentos da propaganda política dos regimes totalitários no século XX. Diante de tais instruções, compreende-se o papel do jornal Deutscher Morgen como veículo publicitário da ideologia nazista e um dos responsáveis pela propaganda política em São Paulo.

Nesse sentido, essa pesquisa parte de uma análise de algumas páginas desse jornal, publicado em São Paulo, pela primeira vez em

\footnotetext{
${ }^{4}$ RAHMEIER, Andrea H. Petry. Relações diplomáticas e militares entre a Alemanha e o Brasil: da proximidade ao rompimento. (2009). Tese de doutorado. Programa de Pós-Graduação em História. PUC-RS. p. 44

5 QUEIROZ; CARRILHO, Op. Cit. p. 107

${ }^{6}$ Apud QUEIROZ; CARRILHO, op. Cit., p. 111.
} 
16 de março de 1932. Um de seus proprietários era Herbert Sack ${ }^{7}$, brasileiro descendente de alemães. Jornalista, químico e representante comercial, foi diretor e secretário do Partido Nazista em 1934. De início, situava-se no bairro da Móoca em São Paulo e a redação do jornal dividia sua sede com a Editora Aurora Alemã. O jornal era impresso pela gráfica Wenig ECia, uma vez por semana. Em 1939, Sack, Ernst e Ernestina Sommer tornaram-se sócios e compraram uma gráfica na Rua Vitória, também na capital. Dali para frente, passaram ali a imprimir os jornais, folhetos e outros impressos panfletários publicados pela empresa ${ }^{8}$.

Por conta do inquérito policial, foram apreendidos nas dependências da editora, em 23 de dezembro de 1940, um grande volume de impressos que divulgavam a "grandiosidade" da Alemanha, exaltavam o nazismo e criticavam os ingleses. Entre eles havia panfletos e folhetos como My Lord! e Livro Branco Alemão; além de livros como Poemas Germânicos, de Lacerda Ortiz, e uma publicação oficial do governo alemão de 1940, intitulada Novos Documentos sobre a Política de Alastramento da Guerra e das Potências Ocidentais?. A editora Aurora Alemã também era responsável pela publicação do almanaque-anuário Volk und Heimat, igualmente difundido na comunidade germânica e disseminador de ideias antissemitas, antibolchevistas e pró-hitleristas.

A última publicação do jornal foi em 7 de novembro de 1941. Em 29 de janeiro de 1942 (mesmo dia da declaração de rompimento de relações do Brasil com o Eixo, ao fim da Conferência dos Chanceleres

${ }^{7}$ Herbert Sack também aparece nos arquivos policiais como um dos proprietários da empresa Estrada de Ferro Alemãs, do Rio de Janeiro, que também publicava impressos de caráter nazista (PERAZZO, 1999).

8DIETRICH, Ana Maria. Caça às suásticas. Om Partido Nazista em São Paulo sob a mira da Polícia Política. São Paulo: Humanitas/Imprensa Oficial/FAPESP, 2007, p. 317

9 PERAZZO, Priscila F. O perigo alemão e a repressão policial no Estado Novo. São Paulo: Arquivo Público do Estado de São Paulo, 1999. 
Americanos no Rio de Janeiro) foi proibido pelo DIP (Departamento de Imprensa e Propaganda do Governo Vargas) de circular. Depois disso, acusados de propagandear a ideologia nazista, seus proprietários foram presos.

Nesse sentido, pretende-se aqui analisar algumas das publicações do jornal Deutscher Morgen, quanto do anuário Volk und Heimat, identificando elementos das suas composições pelos quais se possa identificar os discursos do nacional-socialismo de Hitler. A propaganda nazista de Goebbels se sustentava pela palavra e pela imagem ${ }^{10}$. Desde a diagramação, até o conteúdo de matérias, fotos, desenhos e publicidade de empresas anunciantes, o propósito desse trabalho é perceber como o jornal Deustcher Morgen veiculou, disseminou, propagandeou a ideologia nazista para seus leitores alemães no Brasil.

\section{O Füber, o povo e a pátria}

O Deustcher Morgen foi lançado como um jornal a serviço do Partido Nazista. Produzido no Brasil, em São Paulo, teve estampada na capa da primeira publicação a fotografia de Adolf Hitler e os símbolos da suástica e da águia (animal que representa força e valentia para os alemães e os remete à tradição militar prussiana), além da fonte em estilo gótico, que também se associa a ideia de germanidade. Esses elementos são de especial importância para a compreensão da mensagem que o veículo desejava transmitir ao seu público; trata-se da formação do Deutscher Morgen enquanto marca e o estabelecimento de ideologias que compõem sua identidade enquanto jornal.

A escolha da fonte, da cor, a localização na página, isto é, a forma como a marca é oferecida, se é envolta por espaço em branco

${ }^{10}$ RAHMEIER, Op. cit. 
ou se divide a área do topo com outros elementos, são itens que conformam a apresentação do jornal o e são princípios formadores de sua identidade ${ }^{11}$.

O jornal reproduzia os discursos de Adolf Hitler. Assim, a "voz" do Führer rossoava em São Paulo não apenas pelas ondas do rádio, mas pelas letras impressas do "amanhecer" alemão. Essa publicação ocorreu um ano antes da tomada de poder da Alemanha por Hitler, o que pode levar à interpretação de que não se tratava aqui de alinhamento com o governo da Pátria Mãe, mas uma simpatia deliberada pela ideologia nazista. Para não deixar dúvidas, no expediente, se apresentava como a "Folha Semanal do Partido Nacional Socialista para o Brasil"12.

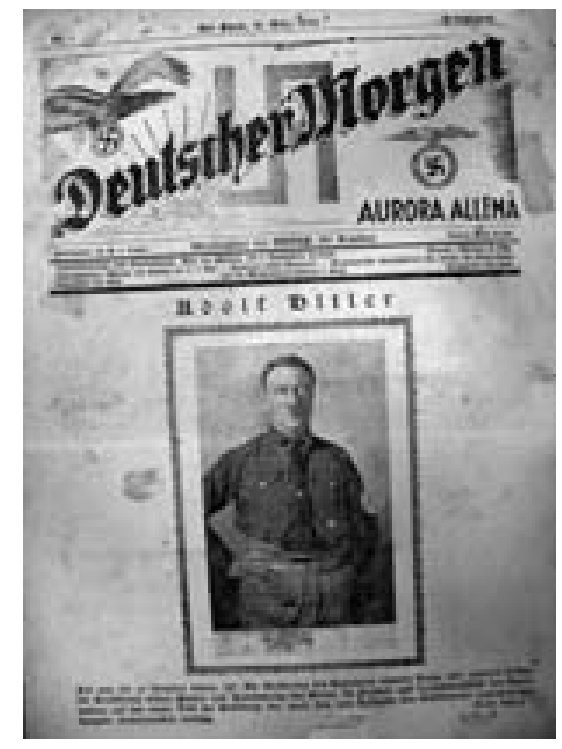

Primeira página da primeira edição do Jornal Deustcher Morgen. São Paulo, 16/03/1932. Coleção Deustcher Morgen, Acervo Instituto Martius Staden, SP.

11 DAMASCENO, Patricia Lopes. Design de Jornais: projeto gráfico, diagramação e seus elementos. Biblioteca On-line de Ciências da Comunicação, Covilha, 2013., p. 16

12 DIETRICH, Op. cit., p. 289 
Nas edições seguintes, manteve a mesma linha editorial e Hitler fora novamente manchete do jornal, pois "aparece como o homem com o poder de libertar e levantar a Alemanha"13. E Hitler parecia ter presença assídua no jornal. Era sempre notícia ou ilustrava as notícias. Sua imagem aparece diversas vezes.

Em 6 de julho de 1934, já com dois anos de veiculação do jornal, o Füher apareceu cumprimentando uma menina loira, em trajes de camponesa, cuja paisagem atrás indicava mesmo estar a garota numa região agrícola. Em 1934, o chanceler já havia tomado o poder na Alemanha e o nazismo já era uma realidade política e partidária, diferente de 1932, ano de lançamento do jornal.

A imagem de Hitler com a menina camponesa compõe a matéria que anuncia a publicação do Anuário de 1934, editado pela empresa Deustcher Morgen, chamado Volk um Heimat. Além do jornal, semanal, a Editora do Deustcher Morgen (Aurora Alemã) também publicou, ao longo da década de 1930, esse anuário (Jabrbuch) chamado Volk und Heimat (Povo e Pátria). Essa publicação anual trazia no nome duas importantes palavras da ideologia nazista: Volk, que quer dizer povo, e Heimat, que quer dizer pátria. Assim, a figura da menina cumprimentada por Hitler faz remissão ao povo jovem alemão, de origem trabalhadora nos campos, alusão à importância do solo e da terra para a pátria.

Analisados três exemplares desse almanaque - 1936, 1937 e 1939 vê-se tratar de um impresso em formato de livro, que continha um calendário anual e páginas para anotações como se fosse uma agenda. Entremeados estavam diversos textos longos sobre cultura alemã, ideário nacional-socialista e pangermanismo. Poemas e letras de canções também compunham os anuários. E vários textos e fotos sobre as diversas colônias alemãs pelo Brasil. Voltados para os alemães no exterior, tratavam de história e cultura brasileira, expunham fotos

13 DIETRICH, Op. cit., p. 293 
de localidades brasileiras, como por exemplo na edição de 1939, em que apareciam Porto Alegre e a Praia de Torres, no Rio Grande do Sul e personagens da História do Brasil Imperial, como D. Pedro I, o Marquês de Barbacena e o Barão de Capanema ${ }^{14}$, num texto escrito por Friedrich Sommer, da família de proprietários da editora.

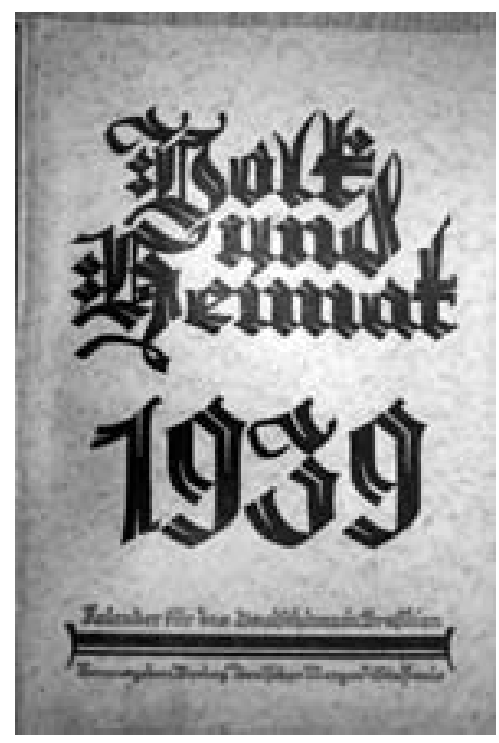

Capa do anuário de 1939 Volk und Heimat. Jahrbuch des Deutschtums in Brasilien.

São Paulo: Editora Deustcher Morgen. Acervo Instituto Martius Staden (SP).

\section{"A Guerra das Falsidades"}

Os proprietários do jornal, juntamente com Hans Henning von Cossel, chefe do Partido Nazista no Brasil, desde 1934, acreditavam que era necessário que houvesse um órgão no exterior que publicasse notícias, consideradas por eles, mais verídicas sobre a Alemanha ${ }^{15}$.

14 Volk und Heimat. Jahrbuch des Deutschtums in Brasilien. São Paulo: Editora Deustcher Morgen, 1939. Acervo Instituto Martius Staden (SP).

15 DIETRICH, Op. cit. 
E foi o Deustcher Morgen um desses veículos que se prestou, também, a essa tarefa: da contrapropaganda. No período da Segunda Guerra Mundial, sobretudo, em que as notícias sobre o inimigo também eram como "armas de guerra", o jornal manteve uma coluna na primeira página (que a partir de 1940 também era escrita em português), sobre as mentiras que os Aliados divulgavam sobre a Alemanha no conflito mundial.

O Brasil e toda a América Latina eram um campo de batalha em que Estados Unidos e Alemanha, principalmente, buscavam domínio ideológico. Bertonha ${ }^{16}$ (2000) aponta uma série de relatórios enviados pelo Consulado Italiano de São Paulo à Embaixada em 1941, com informações acerca das atividades de propaganda do Eixo veiculados no Brasil. O esforço alemão, bem como de outros países pode ser observado no relatório de 14/10/1941, que traz uma interessante tabela na qual consta o número de telegramas publicados por cada agência de notícias nos jornais de São Paulo, Santos e Campinas em agosto/1941:

\begin{tabular}{|l|l|l|}
\hline AGÊNCIA & N. TELEGRAMAS & CM DE COLUNAS \\
\hline Agência Nacional (Brasil) & 1.961 & 16.536 \\
\hline Associated Press (EUA) & 1.847 & 8.734 \\
\hline DOMEI & 232 & 1.901 \\
\hline HAVAS (França) & 3.877 & 22.695 \\
\hline RDV & 111 & 1.592 \\
\hline Reuter (Reino Unido) & 9.928 & 68.275 \\
\hline United Press (EUA) & 10.689 & 48.378 \\
\hline Transocean (Alemanha) & 5.279 & 38.097 \\
\hline Stefani (Itália) & 3.071 & 17.933 \\
\hline
\end{tabular}

(Fonte: BERTONHA, Op. cit., p. 104)

16 BERTONHA, João Fábio. "Divulgando o Duce e o fascismo em terra Brasileira: a propaganda italiana no Brasil, 1922-1943”. Revista de História Regional. Ponta Grossa: v. 5 , n. 2 , p. $83-112,2000$. 
A agência alemã Transocean está em terceiro lugar no número de telegramas publicados nos jornais no Brasil, atrás apenas das agências norte-americana e inglesa. Por esses dados, pode-se perceber como a guerra também se tratava nas páginas dos jornais e quanto era importante o papel dos meios de comunicação à época.

Como a contrapropaganda utiliza-se de técnicas que visam amenizar possíveis impactos de mensagens opostas e procura demonstrar que as ideias contrárias às suas estão em contradição com a realidade tentando fazer com que os leitores não reconheçam nelas nenhuma verdade $^{17}$, a coluna "Guerra das Falsidades" tinha um espaço privilegiado no jornal, logo à primeira página. Escrita em português e em alemão, procurava desmentir ou esclarecer as notícias que a Alemanha alegava como falsamente produzidas pela Grã-Bretanha ou pelos Estados Unidos (os Aliados). Trechos das matérias, em português, tratavam do "quadro negro" da situação. Começava o texto por acusar que:

"O excesso em materia de mentiras é um característico seguro da liberdade ingleza sem o qual não se poderia imaginar esta. Pela democratização progressiva, o povo na Inglaterra chegará a ponto de adquirir um direito á mendacidade”. Estas palavras dão que pensar hoje em dia. Foram escriptas, há mais de 200 annos, por um homem que muito contribuiu para diffundir em todo o mundo a glória da Inglaterra (sic). ${ }^{18}$

E segue a matéria referindo-se à autoria desse trecho à Jonathan Swift, autor das Viagens de Gulliver, que como Bernard Shaw, outro

\footnotetext{
17 QUEIROZ; CARRILHO, Op. cit., p. 114.

18 Início da coluna "Guerra das Falsidaes", do Jornal Deustcher Morgen. São Paulo, 05/01/1940. Coleção Deustcher Morgen, Acervo Instituto Martius Staden, SP.
} 
escritor da literatura inglesa, já demonstrava o caráter dos ingleses, considerado pelos jornalistas aqui como mentirosos.

Interessante notar que, nesse momento, o jornal publicou suas matérias tanto em português quanto em alemão. E, a partir de novembro de 1941 publicou o jornal inteiramente em português ( $\mathrm{n}^{\circ}$ 45 de 07/11/1941).

É interessante discutir o fato de o Deustcher Morgen ter publicado matérias e depois todo o jornal em português. Uma primeira interpretação nos leva a pensar que o jornal passou a cumprir, mesmo que três anos depois, as determinações da legislação brasileira de 1938. O decreto-lei . $^{\circ} 383$, de 18/04/1938 proibia a atividade política de qualquer estrangeiro no Brasil, impedindo a organização, criação ou manutenção de associações, fundações, empresas ou clubes estrangeiros de caráter político para fins de propaganda e difusão "entre os seus compatriotas, de ideais, programas ou normas de ação de partidos políticos do País de origem"19.

O governo brasileiro havia dado o prazo até o final de julho de 1941 para que todos os veículos de língua estrangeira passassem a publicar no idioma nacional (em português). Segundo Rahmeier ${ }^{20}$, "a produção jornalística alemã tinha seus objetivos, mas o governo brasileiro tentou proibir a divulgação das ideias e dos ideais nazistas com leis restritivas".

Por sua vez, sabe-se da importância que governo e cidadãos alemães atribuíam à língua e sua manutenção entre os alemães do exterior era um dos objetivos das ações de diversos governos alemães, mesmo antes do Terceiro Reich. Deustcher Morgen não fora cumpridor da legislação brasileira de imediato, pois só publicou uma edição inteiramente em alemão em novembro, quatro meses após a

\footnotetext{
19 PERAZZO, Op. cit., p. 45

20 RAHMEIER, Op. cit., p. 219
} 
determinação do Governo Brasileiro. Diante desses fatos, percebe-se a resistência do jornal em manter sua publicação em alemão:

As resistências verificavam-se também no funcionamento de instituições sob o controle de grupos que conservavam autonomia em relação ao Estado, na tentativa de fazer funcionar uma imprensa em língua alemã, bem como manter a edição frequente de periódicos ${ }^{21}$.

Preocupou-se com a proibição da língua pouco tempo antes de ser fechado e ter seus proprietários presos e não se furtou de publicar, mesmo em português, matérias de cunho político e de propaganda de ideais nacionais socialistas, o que também estava sob a mira da legislação nacionalista de Vargas. Assim, pode-se pensar na hipótese de que publicar em português foi, na última hora, uma tentativa de "sobrevivência" do jornal, não para apenas para poder continuar funcionando, mas, principalmente, para poder continuar comunicando sua ideologia aos alemães do exterior. Um último sopro de vida.

Mas já não havia mais tempo para esse veículo, pois seu último número circulou em 19 de dezembro de 194122. Alguns meses depois seus proprietários foram presos 23 .

Nesse momento já se podia sentir os efeitos dessa legislação na comunidade alemã. Escolas já haviam sido fechadas ou nacionalizadas, já não podiam mais falar em alemão nas ruas, nos bares, nos clubes, nas rodas com amigos. As crianças já não ouviam a língua a não ser de seus pais e, na escola, essa geração não aprendeu o

${ }^{21}$ CAMPOS, Cynthia Machado. A política da língua na era Vargas. Campinas: Ed. Da Unicamp, 2006, p.18

22 DIETRICH, Op. cit., p. 304.

23 PERAZZO, op. cit. 
alemão formalmente (leitura e escrita). Nesse sentido, para continuar a doutrinar (e mesmo, a funcionar com a empresa) talvez os editores do jornal tenham-se dado conta que precisavam fazer diferente, transformar o que era tradicional, inovar. E assim publicaram o Deustcher Morgen em português. Era a hora da Aurora Alemã. Mas para a aurora já era tarde e o crepúsculo se abateu sobre o jornal e seus proprietários. O Deustcher Morgen não resistiu aos fatos que se sucederam a partir de 1942 .

\section{Os anunciantes}

A publicação impressa também contava com uma série de anunciantes e publicidades de empresas que foram investigadas como difusoras, patrocinadoras ou simpatizantes do nazismo no Brasil. As empresas que anunciavam suas publicidades eram: Sindicato Condor (aviação), Casas Pernambucanas (da família de suíços alemães no Nordeste brasileiro), Estrada de Ferro Alemãs, Banco Germânico, Banco Alemão Transatlântico, AEG Cia Sulamericana de Eletricidade, Theodor Wille \& Co., entre outras.

Além desses anunciantes, havia inúmeros outros que publicavam também no Deustcher Morgen e no anuário Volk und Heimat. O que se pode supor a esse respeito é que, em primeiro lugar, a Editora Aurora Alemã contava com uma carteira de parceiros e, possivelmente, desses anúncios conseguia o sustento da publicação.

$O$ que se percebe é que algumas dessas empresas anunciantes foram acusadas, processadas ou fechadas por ligações com a ideologia e o Partido Nazista no Brasil.

É o caso dos bancos como o Alemão Transatlântico e o Germânico, que foram acusados de financiar propaganda nazista em São Paulo e no Rio de Janeiro. Em setembro de 1942, a Polícia Política enviou um relatório aos interventores federais nos estados acusando 
o Banco Germânico da América do Sul de "exercer catequese sobre cidadãos brasileiros, distribuindo distintivos e escudos nazistas e exercendo visível pressão sobre os elementos não simpatizantes do Eixo". Enquanto isso, o Banco Germânico de São Paulo foi acusado de intermediar transações econômicas da Alemanha para supostos espiões na cidade, como pagamento de despesas relacionadas a essa atividade ${ }^{24}$.

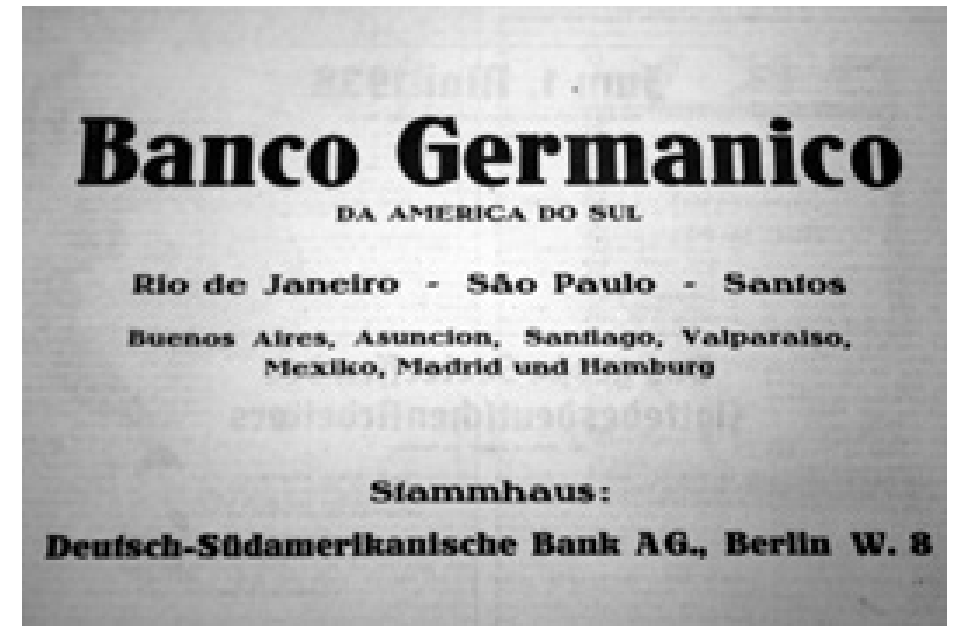

Publicidade do Banco Germânico da América do Sul nas diversas edições do Jornal Deustcher Morgen. São Paulo, 1940. Coleção Deustcher Morgen, Acervo Instituto Martius Staden, SP.

Do Banco Alemão Transatlântico sabe-se que seus diretores eram filiados ao Partido Nazista em São Paulo e no Rio de Janeiro e foram presos por isso, após 1942. Otto Braun, um de seus funcionários, foi tesoureiro do Partido Nazista em São Paulo, exercia uma fiscalização sobre a diretoria do banco e relatava ao consulado alemão as irregulares ali identificadas. Os diretores da filial paulista do banco também foram acusados de nazistas e presos. A Polícia Política,

${ }^{24}$ PERAZZO, op. cit., pp. 75-76. 
ao investigar suas atividades, descobriu que os diretores do banco arrecadavam dinheiro para o Partido:

Uma das atividades em prol do Partido Nazista, praticada na sede do Banco Alemão Transatlântico, era a arrecadação de dinheiro. [...], anualmente, corria uma lista entre os empregados alemães para que fizessem, por determinação da agência do banco, contribuições obrigatórias para associações alemãs ${ }^{25}$.

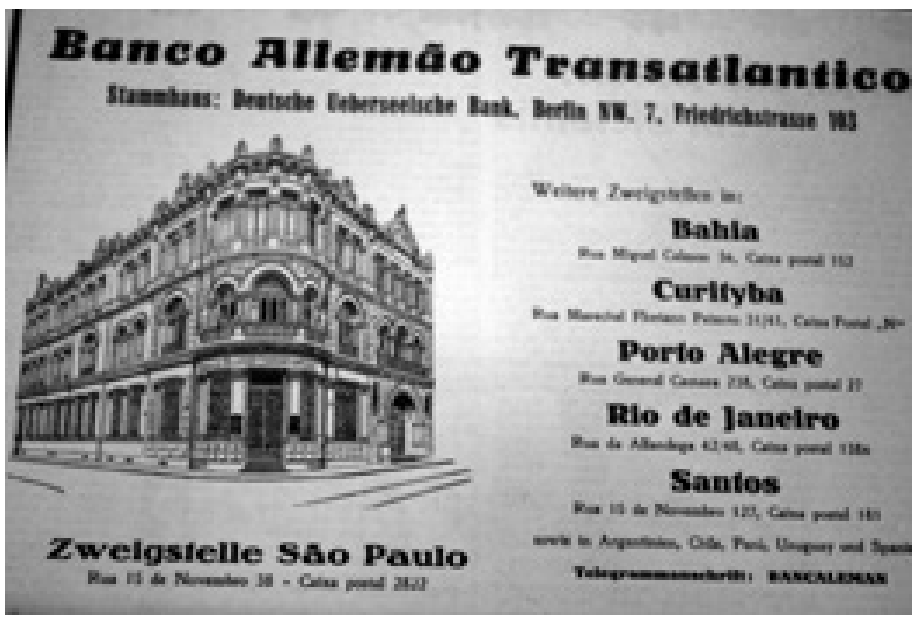

Publicidade do Banco Alemão Transatlantico nas diversas edições do Jornal Deustcher Morgen. São Paulo, 1940. Coleção Deustcher Morgen, Acervo Instituto Martius Staden, SP.

A empresa Theodor Wille \& Co. era uma empresa comercial de exportação de café, cuja sede ficava em Santos. A Theodor Wille teve diferentes participações na vida dos alemães no Brasil, além das suas atividades comerciais. Por ela, os salários dos ex-tripulantes do navio alemão Windhuk, aportado em Santos em 1939 e depois vendido ao Lloyd Brasileiro em 1942, foram pagos até que os marinheiros fossem recolhidos ao campo de concentração para "súditos

25 PERAZZO, op. cit., p. 79. 
do Eixo" de Pindamonhangaba e Guaratinguetá. Mas, o que mais comprometeu a empresa foi seu envolvimento e suposto financiamento das ações de espionagem de alemães no $\operatorname{Brasil}^{26}()$.

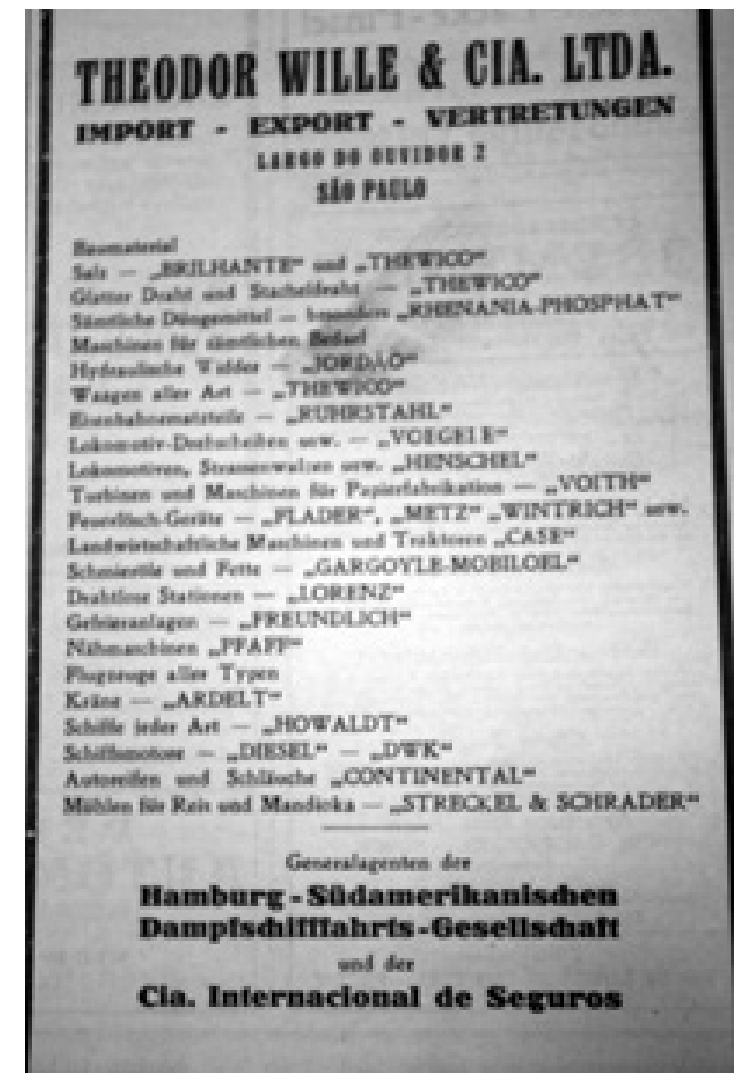

Publicidade da Empresa Theodor Wille nas diversas edições do Jornal Deustcher Morgen. São Paulo, 1940. Coleção Deustcher Morgen,

Acervo Instituto Martius Staden, SP.

Assim, o que se vê nas páginas do jornal, além da ostensiva propaganda política, é uma rede de contatos articulada na cidade de São Paulo.

26 PERAZZO, op. cit. 
A Aurora Alemã, como empresa, atuou como um dos principais personagens da disseminação do nazismo em São Paulo. Seus proprietários se relacionavam com professores e diretores de escola, com banqueiros e empresários alemães, com oficiais consulares e com o chefe do Partido Nazista na capital. Eram também responsáveis pela empresa de comunicação que publicava panfletos, livros, almanaques e um jornal semanal. Pelo que nos apresenta Domenach ${ }^{27}$, a alvorada nazista se cercou de "poderosos" instrumentos da comunicação nas décadas de 1930 e 1940, pois conjugou o impresso (em diversos formatos), com a palavra e a imagem, possibilitando, com isso, o espetáculo da ofensiva nazista em térreas brasileiras.

\section{Considerações Finais}

Enquanto veículo de livre circulação por quase dez anos, o Deutscher Morgen representou um importante espaço de infiltração do nazismo na comunidade alemã paulista. Publicado em alemão, destinava-se à leitura de quem entendesse a língua. Publicado em português, destinava-se aos alemães no exterior. Serviu como veículo de informação, reportagem, mas, sobretudo, de propaganda, pois a notícia era veiculada como publicidade. Parecia ser esse o propósito do jornal. Mais que noticiar ou informar, propagandear.

Com relação ao seu caráter doutrinário, é difícil dimensionar o alcance de sua propaganda política, ainda que, nas décadas de 1930 e 1940, a comunidade alemã radicada em São Paulo dominasse o idioma da pátria-mãe. Por não se tratar aqui de um estudo de recepção, não se sabe como essa publicidade jornalística, de ideologia nacional-socialista, conviveu entre os alemães de São Paulo, de forma

27 Apud QUEIROZ; CARRILHO, op. cit., p. 111. 
geral. Além do Deutscher Morgen, outros jornais como Deutscher Zeitung circulavam em São Paulo.

No entanto, o que é possível apreender da análise desse jornal refere-se às engrenagens de propaganda empreendidas em São Paulo para a propaganda ideológica do nazismo para os alemães do exterior. Compreender um discurso composto por texto e imagem, que propagava as utopias nazistas. Dessa forma, esse veículo de comunicação cumpria sua função mediadora entre a comunidade e a ideologia do regime.

Vários indícios demonstraram o caráter nazista do jornal. De antemão, não se furtou em alinhar-se explicitamente como veículo do Partido em São Paulo, logo na sua primeira edição. As imagens de Hitler tinham sempre lugar de destaque. Os textos não disfarçavam suas tendências e os anunciantes concluíam o endosso à rede nazista que se articulou em São Paulo. A prisão de seus proprietários após o alinhamento brasileiro com os Aliados, acusados de propaganda nazista no Brasil e filiação ao partido estrangeiro, é uma reação do Governo Brasileiro à constatação de todos esses indícios apontados.

O que permanece como reflexão dessa breve análise, é que o veiculo de comunicação fora meio de divulgação e difusão da ideologia nazista na comunidade alemã paulista. E por isso, são inegáveis as tentativas de disseminação do nazismo fora da Alemanha, atravassando o oceano e chegando à América do Sul. Os nazistas tinham diversos meios de comunicar seus valores, ideias e ideologia. E souberam, sem dúvida, transformar os meios de comunicação em veículos importantes de difusão de ideias. Editaram jornais e propagandearam ideias. 